\title{
Animal Disease Surveillance and Control: The Indian Perspective
}

\section{Barkha Sharma $^{1 *}$, Singh Parul ${ }^{2}$, Meena Goswami $^{3}$ and Gaurab Basak ${ }^{4}$}

${ }^{1}$ Assistant Professor and Incharge, Department of Veterinary Epidemiology and Preventive Medicine, UP Pandit Deen Dayal Upadhyay Veterinary University (DUVASU), Mathura, UP, India

${ }^{2}$ Assistant Professor, Veterinary Public Health, UP Pandit Deen Dayal Upadhyay Veterinary University (DUVASU), Mathura, UP, India

${ }^{3}$ Assistant Professor, Livestock Production Technology, UP Pandit Deen Dayal Upadhyay Veterinary University (DUVASU), Mathura, UP, India ${ }^{4}$ M.V.Sc Scholar, Veterinary Public Health, Mathura, UP, India

*Corresponding Author: Barkha Sharma, Assistant Professor and Incharge, Department of Veterinary Epidemiology and Preventive Medicine, UP Pandit Deen Dayal Upadhyay Veterinary University (DUVASU), Mathura, UP, India.

DOI: $10.31080 /$ ASVS.2020.02.0054
Received: January 31, 2020

Published: February 27, 2020

(C) All rights are reserved by Barkha

Sharma., et al.

\section{Abstract}

Diseases cause major economic losses through mortality, reduced productivity, lower fertility, condemned products and restricted access to potential markets. Newly emerging diseases including non-contagious animals diseases having potential to cross over from animals to human population or back are being encountered on almost daily basis. This has been time and again proved by emergence of various epidemics like the novel Corona Virus or China virus, Zika virus, Middle East Respiratory Syndrome (MERS), Severe Acute Respiratory Syndrome (SARS), Highly Pathogenic Avian Influenza (HPAI) and swine flu. Approximately 60\% of all known pathogens and $75 \%$ of emerging pathogens are zoonotic in nature, with about $70 \%$ of all emerging zoonotic pathogens being vector-transmitted diseases. Apart from these emerging diseases, diseases like Foot and Mouth Disease, Brucellosis, Tuberculosis continue to pose challenges in today's world. Some of them are classified under Transboundary animal diseases (TADs). The international trade in animal and animal products has become a sensitive issue for both developed and developing countries by posing an important risk for the spread of animal and human pathogens whilst at the same time being an essential activity to ensure world-wide food security and food safety.

Integrated efforts of government and various organizations is the need of the hour in combating the challenges posed by unchecked multilateral trade in animals and animal products. Continued animal disease forecasting, surveillance monitoring and control, thus have a never before role to play in the present scenario. In essence, the epidemiological challenges to an effective surveillance system relate to rapid detection, representative reporting and accurate diagnosis.

Keywords: Animal Disease Surveillance; Diagnosis; Severe Acute Respiratory Syndrome (SARS)

\section{Introduction}

Humans have lived in close contact with animals for ages. Out of 30 or so new infectious agents encounterd within a span of last thirty years worldwide, almost $60 \%$ are zoonotic and more than two-third of these have a wildlife origin. In the wake of emergence of a novel corona virus originating from China in 2019, supposedly from bats, which has already claimed lives of more than 100 people in China and subsequent ongoing epidemic threat to India and other neighboring countries and other epidemics like MERSA (Middle East Respiratory Syndrome) from Saudi Arabia in 2012 and SARS in 2002-03 [1], Avian Influenza, swine flu etc. it has be- come more imperative to dwell deep into the causes which lead to emergence of such diseases. Apart from this, other well established diseases which were thought to be under control are still persisting. The world has already faced devastating economic losses from major outbreaks of TADs such as FMD in Europe [2], classical Swine Fever in Caribbean and Europe in 1996-2002 [3], RP in Africa in the 1980s [4], PPR in India and Bangladesh [5], CBPP in Eastern and Southern parts of Africa in late 1990s [6] as well as RVF in Arabian Peninsula [7]. India was considered free of glanders for eight years after 1998 until there was reemergence of the disease in 2006 [8]. 
In particular, the impacts of such outbreaks have implications in terms of public health, zoonoses, food security, poverty alleviation, sustainable economic development, social equity and stability. With regard to infectious diseases, the facts that approximately $60 \%$ of all known pathogens and $75 \%$ of emerging pathogens are zoonotic in nature, with about $70 \%$ of all emerging zoonotic pathogens representing vector-transmitted diseases is a matter of increasing concern [9]. Impoverished settings mostly found in the tropical developing world are considered as hotspots for these zoonoses [10]. In almost all the newly emerging diseases, the animals seem to be the source of infection, serving as reservoirs [11] for pathogens, as is evident in the case of SARS where civet cats were supposed to be the source of the virus or Nipah virus, where pigs and bats were confirmed as the main culprits.

The causes for the global spate in the disease outbreaks are multiple and intertwined. In the changing world scenario, complex interactions, diverse livestock production system, increasing population density, fast globalization and growing international interdependence are essential but these factors do not seem conducive for the establishment of a healthy environment and might have lead to rise of many emerging and remerging diseases in past three decades years [12]. For instance, the integration of global economy, financial markets and trade has, in many cases, resulted in the spread of diseases hitherto confined to a small area. Right now world is witnessing the spread of a novel Corona virus (COVID-19), a betacoronavirus, which just like SARS-CoV-2 and MERS-CoV, seems to have spilled over from bats. The SARS-CoV-2 emerged in Guangdong Province of China in 2003, spread to more than 30 countries of Asia, Americas and Europe, with a total of 8439 cases and 812 deaths within a span of 7-8 months. Viral adaptations and ecological shifts due to climate change are also among the major drivers of global pandemic threat [1]. Large scale environmental mismanagement, often linked to the demands of international trade, is a major contributor to global environmental problems such as climate change, destruction of ozone layer and loss of biological diversity. In addition to known food borne diseases, public health communities are being challenged by the emergence of newly recognized types of food borne illnesses, often with serious health and economic consequences [13]. The economic impact of HPAI in Southeast Asia was more than 60 bn USD [14] and that of BSE was more than 10bn USD [15]. With a marked change seen in the eating preferences and taste of customers worldwide, food production, manufacturing and marketing have become global industries, thus providing a potential platform for disseminating infectious agents from the original point of processing and packaging to locations thousands of miles away [16]. The risk of spread of animal and human pathogens through international trade of animals and animal products has become a sensitive issue for both developed and developing countries. In 2006, WHO launched the Foodborne Disease Burden Epidemiology Reference Group (FERG), in collaboration with international stakeholders and WHO's Department of Food Safety, Zoonoses and Foodborne Diseases, to build a framework estimating the global burden of foodborne disease (WHO, 2008).

\section{Need of animal disease surveillance}

Animal disease surveillance is a more intense form of monitoring which includes continuous collection of relevant data regarding the disease status of a given population. In disease surveillance, a directed action is involved towards the actual problem [2,17]. Quality and accurate data collection is the basis of disease monitoring and surveillance systems (MO\&SS). Active surveillance includes generation of primary data by actual field surveys whereas passive monitoring or surveillance uses secondary data collected for other purposes. The ultimate goal of disease monitoring and surveillance is to develop a disease control programme (DCP) comprising of effective disease prevention and intervention strategies to reduce the frequency of a specific disease over a period of time [18].

In the light of recent global outbreak of a number of new diseases, an effective surveillance system which can detect disease emergence in human or animal populations anywhere in the world at the earliest time possible and is global in scope is the need of the hour [12]. There is expansion of the world trade dealing in animals and animal products. The concepts of risk assessment and regionalization, and the General Agreement on Tariffs and Trade (GATT), have brought new challenges on the ability of countries with respect to their status of disease control and disease surveillance [19]. More than ever, veterinary services worldwide are faced with uphill task of protecting their country's animal health status, provide sound surveillance information on the occurrence of diseases within their territories, and conduct scientifically valid risk analyses to establish justified import requirements [20]. Effective surveillance systems are sensitive, specific, timely and representative [21]. An integrated system of complementary methods rather than solitary surveillance activity, is necessary. Participatory epidemiological methods and community animal health networks are being integrated as part of routine disease reporting systems. A global disease surveillance system should minimize the opportunity for disease emergence, transmission and spread in both human and animal population. Currently there has been a broad interest in certain aspects of animal disease surveillance such as risk-based surveillance [22], genomic surveillance [23], and spatio-temporal visualization and analysis of surveillance data [24]. Animal disease surveillance can serve as sentinels for bioterrorist or natural infectious disease epidemics [25]. Surveillance systems can also 
contribute to the identification of disease priorities at national and subnational levels and lead to the prompt recognition of emerging disease problems [26].

India, with total livestock population at $\mathbf{5 1 2 . 0 5}$ million, has one of the largest, uncontrolled human and animal populations in the world. Majority of Indian population is agrarian and living in proximity to animals, and thus is most vulnerable to disease outbreaks. We have been categorized as a "hot spot" for emerging infectious diseases (EID), according to a study by the Institute of Zoology, Zoological Society of London. We have seen outbreaks of several emerging and remerging diseases in recent years like Cholera (serogroup 0139) in 1992, plague in 1994, Diphtheria, Nipah in 2001, Chandipur virus in 2003, 04 and 07 and Crimean Congo Haemorrhagic fever in 2011. For us, an effective global disease monitoring and surveillance and a prompt response to any sort of emergency is urgently needed to face the challenge. Sadly, in India, the animal diseases surveillance and monitoring programmes are wholly inadequate and obsolete. This causes frequent breakdown of health barriers resulting in disease outbreaks. Accurate information is very essential to combat livestock diseases and initiate timely disease control strategies by optimal utilization of all the available funds, resources and manpower. To fill the gaps in updated information regarding the status of diseases, there is an urgent need of database software to store, transmit and analyze the generated data to speculate on the current disease scenario.

Thus, Government of India is working with many national and international organizations and agencies to prevent animal disease occurrence. The Integrated Disease Surveillance Project (IDSP) was created in 2004 initially in 101 districts (IDSP, 2015), later expanded to cover the whole country. A wide network of experts including epidemiologists, microbiologists etc are now at beck and call of IDSP. The National Apical Advisory Committee for National Disease Surveillance and Response System (NAAC) was created (WHO, 2003) in 1996. Government has also planned training programmes on the lines of Epidemic Intelligence Services (EIS) of CDC, Atlanta (GOI, 2012) to create highly skilled field epidemiologists. Prime Minister Narendra Modi launched National Animal Disease Control Programme for FMD and Brucellosis on 11 September, 2019 with a total outlay of 12,652 crores from 2019-2024, with aim to control FMD and Brucellosis by 2025 with vaccination and eventual eradication by 2030 . Stress is also being given on the control of infertility, strengthening of state veterinary biological production centers and creation of disease free zones.

Currently, India has over 50,000 veterinary institutions employing around 100,000 veterinarians and paraveterinary staff run by various state governments to provide clinical veterinary and breeding services supported by a wide network of 23,303 polyclinics, 27543 veterinary aid centers and 250 disease diagnostic labs and 26 vaccine producing units (19 under government and 7 under private sector) throughout the country. There are five referral diagnostic facilities including national and regional laboratories with advanced technologies. For Animal Disease Surveillance, information on the incidence of livestock and poultry diseases in accordance with the guidelines of the OIE, is collected, and disseminated in the form of a monthly 'Animal Disease Surveillance Bulletin' to all the states and also to OIE, APHCA etc. The Planning commission is considering a proposal to integrate human and animal disease surveillance programmes, following regular outbreaks of zoonotic diseases like Japanese encephalitis, leptospirosis and H1N1 influenza- all of which have jumped the species barrier and are now endemic in India.

National level agencies/institutes involved in disease monitoring and surveillance

- National Center for Disease Control (NCDC), New Delhi: The National Institute of Communicable Diseases (NICD) was upgraded to National Centre for Disease Control (NCDC) as a centre of excellence with responsibility for enhanced capabilities for rapid response and laboratory based surveillance of communicable diseases (GOI, 2010) to become self sufficient in responding to disease outbreaks, short and long term trainings in field epidemiology have been provided by NCDC since 1963.It serves as the focal point of IHR (international Health Regulations, 2005) in India [27].

- National Institute of High Security Animal Disease (NIHSAD), Bhopal: In 1998, a containment laboratory of Biosafety level 4 (BSL-4) namely High Security Animal Disease Laboratory (HSADL) was established at Bhopal and later upgraded to a national level Institute. It was a BSL3+ laboratory, first of its kind in Asia and tenth in the world, for the diagnosis and control of exotic and emerging animal diseases. It generates base line data regarding each disease prevalent in the country. The laboratory has developed recombinant antigen and monoclonal antibody based competitive ELISA kits for the diagnosis of Bovine Viral Dirahhoea and bovine immunodeficiency, first of its kind in the world [28].

- National Institute of Veterinary Epidemiology and Disease Informatics (NIVEDI), Bengaluru: NIVEDI, formerly PD-ADMAS, was established in 1987 by ICAR under 7th five 
year plan as an AICRP to develop a system for monitoring and surveillance of economically important livestock diseases in the country and to evolve strategic control measures for them. It was granted autonomy on 1st April, 2000 during IX plan and in 2013; was upgraded to a National Institute. Since its inception, NIVEDI has played a crucial role in upgradation of animal disease surveillance in India. It was instrumental in Rinderpest eradication and has envisaged "Vision 2030" to attain freedom from 15 economically important diseases like PPR, Brucellosis, Swine Flu, Swine Fever, anthrax etc. along with focusing on food safety and income security through sustainable livestock health and economics by using tools of epidemiological surveillance (PD ADMAS Vision 2030). It has created a national directory of 6.39 lakh villages for critical epidemiological sampling frames. Innovative and interactive Epitrak software has been developed by ADMAS, utilizing database, GIS and statistical tools to analyze livestock diseases. EpiNET. India is a monthly e-bulletin from NIVEDI that provides top ten disease outbreaks reported for the past two months throughout the country with spatial and temporal distribution of disease outbreak data.

- Center for Animal Disease Research and Diagnosis (CADRAD), IVRI, Bareilly, UP: It is a national level referral laboratory for investigation and diagnosis of livestock diseases. It collects, stores, processes and retrieves animal health and disease data and has established an information bank for immediate disease control and forecasting. The information is made available in the form of bulletin for the use of beneficiaries.

Animal health/disease monitoring programmes implemented by central government

To ensure a disease free status and to be compatible with the standards laid by the OIE, major health schemes have been initiated to support the animal health programs in different states. Further, in order to control the important livestock diseases and to undertake the obligatory functions related to animal health in the country, central government is implementing various schemes

\section{National Surveillance Program for communicable disease} (NSPCD): It is a centrally sponsored program in India, initiated in 1997-98 with National Center for Disease Control (Formerly NICD) as nodal agency in 101 districts in the country with an objective of strengthening district and state functionaries to identify and respond to disease outbreaks and minimize further economic losses.
2. National Animal Disease Referral Expert System (NADRES): NADRES, a web based dynamic and interactive livestock disease rational database, was a combined outcome of a project on weather based animal disease forecast (WB-ADF) supported by GIS for national level disease forecasting by passive surveillance using the data generated by state animal husbandry and other departments and the 'Animal Health Information System through Disease Monitoring and Surveillance (AHIS-DMS).' It generated active surveillance data through village surveys. It was formally launched by NIVEDI in the year 2000 under tenth five year plan for national level disease forecasting for the first time in the country. It is devoted especially to forecast 15 major livestock diseases. The disease situation can be predicted two months in advance at district level so that preventive measures can be taken well in time by the concerned authorities. This software addresses the need for data collection, transmission, retrieval, analysis of critical disease events as and when they occur and is useful for field veterinarians, administrators, technocrats, research personnel, farmers, veterinary colleges and students.

3. The National Animal Disease Reporting System (NADRS): It is a platform for reporting data related to occurrence of animal diseases from the Block level Veterinary Units for better monitoring and control of trans-boundary diseases (Disease Reporting through SMS, email and web based interface). It was initiated by Department of Animal Husbandry, Dairying and Fisheries (DADF) during 2010-11 through the National Informatics Centre (NIC). Around 143 animal diseases scheduled in the Prevention and Control of Infectious and Contagious Diseases in Animals Act, 2009 are included in this reporting system. The project is being funded by the Union government with a grant of Rs 104.05 crore. The project work is going on successfully in the states of Rajasthan, Delhi, Gujarat, Kerala and Andhra Pradesh

4. Integrated Disease Surveillance Project (IDSP) was launched by the Ministry of Health and Family Welfare in November 2004 with the aid of World Bank. It is a decentralized, State based Surveillance Program in the country, intended to detect early warning signals of impending outbreaks and help initiate an effective response in a timely manner.

5. All India Network Program-Blue Tongue: It was a 3 year collaborative Indo-UK project with participating centers as UK dept for International development (DFID), Biotechnology and Biological Sciences Research Council (BBSRC) and Scottish Government via Combating Infectious Diseases of Livestock for International Development (CIDLID). The project was coordinated by The Pirbright Institute (TPI), London and ICAR. 
6. Brucellosis Control Program (BCP): Brucellosis causes an annual loss of INR 350 million/year. Thus BCP was introduced by the Govt of India in $10^{\text {th }}$ Five Year Plan (FYP). Earlier known as National Control Programme on Brucellosis, was renamed as BCP in $12^{\text {th }}$ FYP. It includes calfhood vaccination of female calves of 6 - 8 months of age in all states by cotton strain 19 vaccine, biannual village level screening of pooled milk samples, mass screening and castration of infected bulls (DADF, 2015).

7. Foot and Mouth Disease Control Program (FMD-CP): To prevent economic losses due to FMD which amounts to Rs 18000 crores annually, and to develop herd immunity in cloven footed animals, FMD-CP was started in $10^{\text {th }}$ Plan in 54 districts of India covering 30 million cattle, buffaloes and pigs. It was later expanded to cover 221 districts targeting 120.85 million animals. During $12^{\text {th }}$ plan, further expansion in the whole country's 316 million animals of 640 districts is on cards. The program is $100 \%$ funded by the center towards cost of vaccine, maintenance of cold chain and other logistic support to undertake vaccination. The state govts provide other infrastructure and manpower [29]. By repeated mass vaccination twice a year, aim is to achieve freedom with vaccination status by 2030 .

\section{- National Project for RinderPest Surveillance and} Monitoring (NPRSM): Formerly it was named as National Project on Rinder Pest eradication (NPRE): In 1989, Government of India, under bilateral collaboration with the European Union launched a project ALA/89/04 for strengthening of veterinary services for eradication of Rinderpest (RP) as part of FAO's concept of South Asia Rinderpest Eradication Campaign (SAREC) as a component of worldwide efforts for Global Rinderpest Eradication Program (GREP). Consequently the National Project on Rinderpest Eradication (NPRE) was launched in India in 1990. Implementation began in May 1992 and the project adopted the "OIE Pathway" towards Rinderpest eradication in 1993-94. The first stage i.e. provisional freedom from RP for the whole country was achieved w.e.f $1^{\text {st }}$ March 1998. India was declared "free from Rinderpest disease" on May 22, 2004 and finally on May 25, 2006, India was declared "free from Rinderpest infection. Another disease to be targeted for eradication under this project was Contagious Bovine Pleuro Pnuemonia (CBPP) whose eradication was initiated in 8 districts of Assam. India was declared provisionally free from CBPP from October 2003, yet to maintain this status, a continu- ous sero monitoring and surveillance is being carried out.

8. PPR-Control Programme: Started in 2010 with $100 \%$ central assistance and was extended to all the states under $12^{\text {th }}$ FYP.

9. Classical Swine Fever-CP: CSF is enzootic mostly in pig producing NE states of our country. Initiated during $10^{\text {th }} \mathrm{FYP}$, it mainly targets North east, with $100 \%$ funding for CSF vaccine.

10. Directorate of Animal Health: This is a Central sector Scheme having following components

- Animal Quarantine and Certification Services

- Central/Regional Disease Diagnostic Laboratory

- National Veterinary Biological Products Quality Control Centre.

- Preparedness, Control and Containment of Avian Influenza (added during the $11^{\text {th }}$ Plan)

a. Animal Quarantine and Certification Services (AQCS): The main objective of this scheme is to prevent ingress of livestock diseases into the country by regulating the import of livestock and livestock products and to issue export health certificate as per international norms for livestock and livestock products, which are exported from India. Four Animal Quarantine and Certification Service Stations, one each at New Delhi, Chennai, Mumbai and Kolkata have been established. These stations also provide export certificates of international standards for livestock and products exported from India. It has been decided to strengthen bio-security in the livestock sector through setting up of two additional animal quarantine stations at Hyderabad and Bangalore and also strengthening of core existing quarantine stations through setting up of additional quarantine units at operational areas of airports, seaport and International Container Depots (ICDs) at Delhi, Mumbai, Kolkata and Chennai.

b. Central/Regional Disease Diagnostic Laboratories: At present one Central and five Regional Diseases Diagnostic Laboratories located at Izatnagar, Bangalore, Pune, Kolkata, Jalandhar and Guwahati are fully operational. The Regional Disease Diagnostic Laboratories provide expert disease investigation to states and UTs on regional basis. The Central Lab- 
oratory coordinates the technical execution of the Regional Laboratories.

c. National Veterinary Biological Products Quality Control Centre: In order to assess the quality of vaccines and biologicals, a National Veterinary Biological Products Quality Control Centre is being set up at Baghpat, Uttar Pradesh. The Institute recommends licensing of manufacturers of veterinary vaccines, biologicals, drugs, diagnosis and other animal health preparations in the country, establishes standard preparations to be used as reference materials in biological assays and ensures quality assurance of the veterinary biologicals produced indigenously and imported.

d. Preparedness, Control and Containment of Avian Influenza: This was a World Bank assisted project for the control of Avian Influenza with the budgetary outlay of the project at Rs.134.78 crore and duration was three years extended for two more years. It was implemented since the first year of the $11^{\text {th }}$ Plan i.e. 2007-2008.

11. Livestock Health and Disease Control (LH and DC): A centrally sponsored scheme implemented during $10^{\text {th }}$ plan with an outlay of 525 crores. The scheme has following components.

\section{Assistance to states for Control of Animal diseases (ASCAD)}

Assistance is provided to state govts to control economically important livestock and poultry diseases by immunization, strengthening of existing state Veterinary Biological Production units, Disease Diagnostic Laboratories, holding workshops/seminars and in-service training to Veterinarians and paravets. The programme envisages collection of information on the incidence of various diseases from states and Union Territories and compile the same for the country. The programme is being implanted on 75:25 sharing basis between the centre and the states with following objectives.

- To control emerging, exotic as well as existing diseases of the state

- Training of field veterinarians and paraveterinarians.

- Surveillance and monitoring of diseases and preparation of disease forecasting models

- Information and communication campaign and community participation.

\section{Professional efficiency development (PED)}

The objective of this scheme is to regulate veterinary practice and to maintain register of veterinary practitioners as per the provisions of Indian Veterinary Council Act, 1984 (IVC Act). The scheme envisages establishing Veterinary Council of India at the Centre and the State Veterinary Councils in those states, which adopted the Indian Veterinary Council Act, 1984. At present it is implemented in all the States and Union Territories except Jammu and Kashmir. 100\% Central Assistance is provided to the VCI and the Union Territories and $50 \%$ to the states.

\section{Conclusion}

Control and eradication of major epidemic diseases of livestock in any area of the world is the ultimate necessity and requires a coordinated regional approach. Countries with lower socio-economic standards are liable to fall behind their more developed neighbours in the area of animal disease control. Spatial analyses using a GIS are extremely useful for monitoring disease spread as it can associate the occurrence of a disease with weather conditions, ecological zones or geographic features such as rivers or roads, ponds, marshes etc. This is very necessary to devise effective preventive measure well in advance. Areas under particular threat can be detected early in the development of a disease, enabling the more rational deployment of resources. Planning for staff distribution, transport arrangements and vaccine purchases is to be facilitated. There is a clear inconsistence between demands placed on veterinary services and current level of funding and support they are receiving especially in the developing world [20]. India still has a long way to go before it achieves self sufficiency in the area of disease surveillance and monitoring. Disease reporting is neither timely nor adequate. Reports and returns are time taking and might get lost in transit. Available veterinary services are grossly inadequate and untrained. Lack of awareness in public, lack of proper disposal plans for disease positive animals further aggravate the problem. There is no administrative control on the movement of animals so quarantine and segregation can't be implemented. Meager facilities for disease diagnosis and lack of trained professionals, proper epidemiological studies are a few of numerous obstacles for the creation of health supporting environment. Animal Disease surveillance faces many of the problems encountered by surveillance efforts for human disease to include lack of clear case definitions, fragmented and paper-based information systems, and conflicting governance and regulatory authorities [25]. Inadequate resources, frail diagnostic infrastructure and knowhow, lack of specific government policies and legal framework for surveillance [30] further aggravate the situation. Needless to say, much more effort, openness and collaboration is needed to fully achieve these goals [31]. 


\section{Bibliography}

1. Bond Katherine C., et al. "The Evolution and Expansion of Regional Disease Surveillance Networks and Their Role in Mitigating the Threat of Infectious Disease Outbreaks". Emerging Health Threats Journal 6 (2013).

2. Thrusfield M. Veterinary epidemiology. 3rd Edn. Blackwell Science Ltd. Oxford, UK (2005).

3. Vargas M Teran., et al. "Situation of Classical Swine Fever and the Epidemiologic and Ecologic Aspects Affecting Its Distribution in the American Continent". Annals of the New York Academy of Sciences 1026.1 (2004): 54-64.

4. Vargas TERÁN M., et al. "Situation of Classical Swine Fever and the Epidemiologic and Ecologic Aspects Affecting Its Distribution in the American Continent". Annals of the New York Academy of Sciences 1026.1 (2014): 54-64.

5. Rweyemamu MM., et al. "Future control strategies for infectious animal diseases- Case study of the UK and sub-Saharan Africa". In: UK (2006).

6. Thiaucourt F., et al. "Contagious bovine pleuropneumonia: vaccines, historic highlights, present situation and hopes". Developments in biological standardization 114 (2003): 147-160.

7. Roeder PL and Obi TU. "Recognizing peste des petitis ruminants: a field manual”. FAO Animal Health Manual 5 (1999): 28.

8. Balkhy HH and Memish ZA. "Rift Valley fever: an uninvited zoonosis in the Arabian peninsula". International Journal of Antimicrobial Agents 21 (2003): 153-157.

9. Taylor LH., et al. "Risk factors for human disease emergence". Philosophical Transactions of the Royal Society B (2001): 356.

10. WHO. Report on Neglected Tropical Diseases-Working to Overcome the Global Impact of Neglected Tropical Diseases, First WHO report on neglected tropical diseases. Geneva, WHO Press (2010).

11. Jones KE., et al. "Global trends in emerging infectious diseases”. Nature 451 (2008): 990-993.

12. Dufour B and Hendrikx P. "Epidemiological surveillance in animal health, 2nd Ed". World Organisation for Animal Health, Paris. Government's foresight project, infectious diseases: preparing for the future (2009): 1-24.
13. WHO. Integrated Control of Neglected Zoonotic Diseases in Africa, Report of a joint meeting, ILRI Nairobi, 13-15 November (2007).

14. Brahmbhatt M. "Avian and Human Pandemic Influenza - Economic and Social Impacts". Genèva, Switzerland: WHO, Discussion at the WHO Headquarters on November 7-9 (2005).

15. Scott M., et al. "Transgenetic investigations of the species barrier and prion strains". In Prion Biology and Diseases, 2nd ed. (Prusiner, S. B., ed.). (2004): 435-544.

16. Hulebak K., et al. "Integration of animal health, food pathogen and foodborne disease surveillance in the Americas". Revue Scientifique et Technique 32 (2013): 529-538.

17. Salman MD. "Surveillance and Monitoring Systems for Animal Health Programs and Disease Surveys". Animal Disease Surveillance and Survey Systems (2003): 3-13.

18. Christensen J. "Epidemiological Concepts Regarding Disease Monitoring and Surveillance". Acta Veterinaria Scandinavica 94 (2001): 11-16.

19. Hueston WD. "Assessment of national systems for the surveillance and monitoring of animal health". Revue scientifique et technique 12 (1993): 1187-1196.

20. Zepeda C., et al. "The role of veterinary epidemiology and veterinary services in complying with the World Trade Organization SPS agreement". Preventive Veterinary Medicine 67 (2005): 125-140.

21. Thacker SB., et al. "The Science of Public Health Surveillance". Journal of Public Health Policy 10 (1989): 187-203.

22. Stärk KD., et al. "Concepts for risk-based surveillance in the field of veterinary medicine and veterinary public health: review of current approaches". BMC Health Services Research 6 (2006): 20.

23. Tyagi E., et al. "Development of Genomic Surveillance Bioinformatics Modules". Online Journal of Public Health Informatics 7.1 (2015): e96.

24. Perez A., et al. "Global animal disease surveillance. Spatial and Spatio-temporal”. Epidemiology 2 (2011): 135-145.

25. Wurtz RM and Popovich ML. "Animal Disease Surveillance: A Framework for Supporting Disease Detection in Public Health". Scientific Technologies Corp (2002). 
26. Mariner JC. "Community -based animal health workers and disease sureveillance". In Catley. A., Blakeway, S.L.T., (Eds). Community based Animal Health Care. ITDG Publishing, London, U.K. (2002): 24-272

27. Dikid T., et al. "Emerging and re-emerging infections in India: An overview". Indian Journal of Medical Research 138 (2013): 19-31.

28. Pradhan HK. Animal Disease Surveillance and Control in India with reference to emerging/exotic diseases. Meeting of Experts of the State Parties to the Convention on the Prohibition of the development, Production and Stockpiling of bacteriological (Biological) and Toxin Weapons and on their Destruction. Geneva, 19-30 (2004).

29. Ahuja V., et al. "Animal Health for poverty alleviation: A review of key issues for India". Background paper prepared for "Livestock Review of the World Bank" (2008).

30. Bhatia R and Narain JP. "The Challenge of Emerging Zoonoses in Asia Pacific". Asia Pacific Journal of Public Health 22.4 (2010): 388-394.

31. Thierry Lefrançois and Thierry Pineau. "Public health and livestock: Emerging diseases in food animals". Animal Frontiers 4.1 (2014): 4-6.

\section{Assets from publication with us}

- Prompt Acknowledgement after receiving the article

- Thorough Double blinded peer review

- Rapid Publication

- Issue of Publication Certificate

- High visibility of your Published work

Website: www.actascientific.com/

Submit Article: www.actascientific.com/submission.php

Email us: editor@actascientific.com

Contact us: +919182824667 